\title{
Cooperativas de vivienda: experiencia en Uruguay
}

\section{Housing cooperatives: the experience in Uruguay}

\author{
Melissa CABrera \\ Licenciada en Trabajo Social. \\ Diplomada en «Estudios urbanos e intervenciones territoriales», \\ Facultad de Ciencias Sociales, UdelaR
}

DOI: $10.1387 /$ reves.20524

Sumario: I. Desarrollo. 1. Breve presentación sobre el modelo mundial de vivienda en cesión de uso. 1.1. Antecedentes. 1.2. Modelos a nivel mundial. 1.3. Los ejes transversales del modelo. 2. La experiencia de Uruguay. 2.1. Breve reseña histórica del caso uruguayo. 2.2. Las bases del modelo. 3. Algunas claves para el desarrollo de este modelo.--II. Bibliografía.

\section{Resumen}

El objetivo de la presente ponencia es exponer los principales lineamientos del modelo de cooperativa de vivienda en cesión de uso. Al hablar del acceso a la vivienda, como una necesidad básica que nos atraviesa a todas, aparece como una opción relevante pensar la resolución de esta necesidad a través de propuestas colectivas. Es a partir de esto que interesa presentar distintas experiencias que se vienen desarrollando desde hace varios años en distintos países, que promueven un modelo colectivo de acceso a la vivienda, mediante la gestión cooperativa, y que priman el derecho al goce y al uso de la vivienda, por sobre la especulación que hace de la misma como bien mercantilizado.

\footnotetext{
Abstract

The aim of this presentation is to put forward the main guidelines of the housing cooperative model under an assignment of use system. When we talk about access to housing as a basic necessity that affects us all, it feels relevant to consider the option of satisfying this need by means of collective proposals. This is the starting point for presenting different experiences that have been developed for several years now in a number of countries, where a collective model of access to housing is promoted by means of cooperative management, and in which the right to use and enjoy housing prevails over speculation that treats housing as a marketable good.
} 


\section{Desarrollo}

\section{Breve presentación sobre el modelo mundial de vivienda en cesión de uso}

\subsection{Antecedentes}

Podemos decir que los orígenes del cooperativismo están marcados por el contexto de la revolución industrial. Los problemas sociales que implicó este contexto para la clase obrera, fueron propulsores de la lucha y la organización colectiva, que dio lugar a la conformación de las primeras asociaciones cooperativas. En este sentido podemos decir que las cooperativas surgen como reivindicación colectiva, como una propuesta alternativa para hacer frente a las necesidades compartidas por la clase trabajadora.

Intentando recuperar los antecedentes del cooperativismo de vivienda, podemos mencionar por un lado, el pensamiento de los socialistas utópicos y las ideas que desarrollaron en cuanto a la vida en comunidad. Hacemos referencia a la comunidad teorizada por Charles Fourier, «el falansterio»; así como a los experimentos comunitarios del británico Robert Owen (la comunidad New Harmony entre ellos), a partir de lo cual se plantean propuestas de comunidades de consumo, producción y residencia, donde la propiedad es colectiva. Por otro lado, otro antecedente fundamental es la primera asociación cooperativa - de producción, residencia y consumo-, fundada por los pioneros de Rochdale en 1844. Son sus fundadores y fundadora, quienes formulan los llamados principios cooperativos de Rochdale, estableciendo las bases del cooperativismo actual.

Estos antecedentes dan cuenta de que el cooperativismo tiene su origen en la búsqueda de una solución colectiva a necesidades sociales compartidas, entre ellas el acceso a la vivienda.

\subsection{Modelos a Nivel MUNdial}

La principal ola del cooperativismo de vivienda por cesión de uso data de los ańos 70-80 del siglo pasado. Podemos mencionar cuatro modelos como los más destacables que se desarrollan hasta hoy en día, y que han sido y siguen siendo los modelos que han inspirado el desarrollo de la vivienda en cesión de uso en otros países.

El modelo Andel de los países escandinavos: es un modelo de vivienda basado en la gestión cooperativa y la cesión de uso. La gestión cooperativa facilita la autogestión haciendo que las residencias estén adaptadas a las necesidades de las personas que vivirán allí, teniendo cada residente representación democrática (una persona, un voto) en todas las decisiones respecto a la construcción, y mantenimiento de las viviendas y los espacios 
comunes. La cesión de uso establece que todas las personas de la cooperativa comparten la propiedad, gozando del derecho al uso de la vivienda de forma indefinida, y con posibilidad de traspasar este derecho. Es un modelo muy desarrollado en estos países como una opción viable para sus habitantes, siendo que la administración pública cede el suelo donde se construyen las viviendas, lo cual facilita las condiciones de acceso.

El modelo Wohnprojekte de Alemania: es un modelo que surge en la década de 1970, en la Alemania Federal, y que responde a una forma comunitaria de habitar. Se define como proyectos de grupos de personas que no pueden o no quieren resolver el acceso a la vivienda a través del mercado y de forma individual, por lo cual deciden asociarse para dar respuesta colectiva a la necesidad de vivienda, mediante una solución a un costo accesible para las personas que constituyen el grupo. Incluye espacios de uso comunitario, tanto vinculados a servicios, como a espacios de socialización. También se desarrollan bajo la forma jurídica de cooperativa, y comparten la propiedad colectiva de las viviendas.

El modelo Canadiense: desde los años 70, la población de Canadá con necesidad de vivienda, comienza a incitar al Gobierno a cambiar la política de acceso a la vivienda, lo cual devino en un programa basado en la concesión de terrenos por parte del estado para que grupos locales construyan y gestionen sus propias viviendas sociales sin ánimo de lucro.

Desde el inicio las personas que participan de estos programas utilizan el modelo cooperativo para llevar adelante esta gestión, y es la cooperativa en su totalidad quien ostenta la propiedad de las viviendas. El apoyo desde la administración pública (avalando préstamos, concediendo subvenciones, estableciendo legislación al respecto, entre otros) ha sido clave para el desarrollo de este modelo. En Canadá, las cooperativas de vivienda están plenamente reconocidas como la forma de acceso y gestión de la vivienda más idónea para la población.

El modelo de cooperativa de ayuda mutua de FUCVAM en Uruguay: lo desarrollaremos en el siguiente apartado.

\subsection{Los EJES TRANSVERSALES DEL MOdelo}

Si bien en cada territorio la vivienda por cesión de uso se ha desarrollado bajo distintos formatos, respondiendo a diferencias coyunturales y culturales de cada país; podemos decir que cada uno de estos modelos responde a la idea de dar una solución colectiva al problema de la vivienda, reinventando el acceso a la vivienda impuesto por el mercado (compra o alquiler), logrando primar de esta forma el valor de uso de la vivienda sobre el valor de cambio. A su vez a través de la gestión cooperativa se prima la participación de las personas en la toma de decisiones, desde el diseño 
de las viviendas y los espacios comunes, hasta su uso y mantenimiento. La propiedad recae sobre la cooperativa, y las socias, son quienes gestionan la misma; pueden vivir allí de por vida o no, pero lo principal es que se bloquea la posibilidad a especular, siendo que sólo pueden gozar del uso.

Resumiendo los puntos en común, podemos decir que el modelo de cooperativa en cesión de uso permite:

- Reinventar el derecho a la vivienda desde una propuesta de propiedad colectiva: se rompe con la idea de propiedad privada. El modelo permite el acceso a una vivienda a un precio inferior al del mercado. La propiedad de la vivienda siempre recae sobre la cooperativa, lo cual impide que se pueda hacer un uso especulativo de ésta. Permite un uso indefinido en el tiempo, transmitido y heredado de la vivienda. Este modelo ha permitido acceder a la vivienda a una población que por su situación económica, no puede acceder a la misma por otros medios.

- Participar y autogestionar el derecho a la vivienda: el formato de organización cooperativo, posibilita un diseño democrático, participativo y personalizado de las viviendas y de los espacios comunes. El derecho de uso se obtiene mediante un ingreso inicial (el capital social) y se mantiene mediante un pago mensual asequible, que se reutiliza para sostener el modelo.

- Ampliar el concepto de vivienda, crear hábitat: los proyectos incluyen no sólo la construcción de la vivienda, sino también el diseño de espacios comunes y servicios sociales comunitarios. A su vez, muchas de estas experiencias intentan incorporar la construcción de viviendas con mayor respeto al medio ambiente, en comparación a la oferta del mercado tradicional.

- Incidir en la política pública de vivienda social: como se puede observar en el desarrollo de los distintos modelos, el rol del estado aparece como fundamental para que prospere el modelo. En muchos casos ha sido fundamental poder construir sobre suelos cedidos por la administración pública, haciendo uso de estos suelos sin que la administración pública pierda su propiedad; o accediendo a financiamiento para poder construir. Por otra parte, los modelos antes mencionados han desarrollado experiencias de intercooperación, cooperando con otras cooperativas e incluso organizándose en algunos casos en federaciones y confederaciones, para lograr replicar el modelo de vivienda en cesión de uso.

Es mediante esta organización del cooperativismo como fuerza social organizada que se ha logrado tener incidencia en materia pública y a su vez crear marcos normativos que favorecen el desarrollo de este modelo. 


\section{La experiencia uruguaya}

\subsection{Breve RESEÑa histórica del caso uruguayo}

De los modelos presentados en el apartado anterior, aparece como una experiencia destacable la desarrollada en Uruguay desde finales de los años 60.

Las primeras experiencias de cooperativas de vivienda surgen en 1966 en el interior del país (Salto, Fray Bentos e Isla Mala) con el impulso del Centro Cooperativista del Uruguay (CCU).

Estas tres experiencias se conforman como cooperativas de consumo ya que aún no existía la figura de cooperativa de vivienda. Se promueven las primeras experiencias de cooperativismo de vivienda, colocando la ayuda mutua y la autogestión como pilares de este movimiento social. Este modelo plantea de forma excepcional el entendido de la vivienda como propiedad colectiva.

Estas experiencias pasan a tener un marco jurídico de regulación con la aprobación de la Ley Nacional de Vivienda (N. ${ }^{\circ}$ 13.728) promulgada por el Parlamento Nacional en 1968, que crea el Fondo Nacional de Vivienda con el objetivo de solventar la construcción de viviendas destinadas a los sectores populares.

Interesa mencionar el contexto histórico y político en que se gestan estas experiencias y la promulgación de la Ley. Hablamos de un momento histórico de duro enfrentamiento social en el país entre la oligarquía nacional (los dueńos de la tierra y el capital financiero) por un lado, respaldada por un gobierno de clase que los representaba y defendía; y los trabajadores y las trabajadoras por el otro (Nahoum; 2013). El contexto era de crisis, de liberalización económica, autoritarismo político, congelamiento de salarios, desregulación del mercado laboral. Y ante este panorama la resistencia social se organiza de muy diversas formas en todo el país, para hacer frente a las intenciones de usurpación del imperialismo y la clase dominante del país.

Aparece la ley como una excepción, una suerte de contradicción con el momento histórico que la genera: se pasa a reconocer la vivienda como un derecho universal. Aunque la ley surge con otros intereses vinculados a las clases altas, y el capítulo de cooperativas de vivienda aparece como algo marginal; para las interesadas en este modelo (la clase trabajadora), implicó la conquista derechos.

La Ley pasa a definir el marco organizativo e institucional de las cooperativas, así como su financiamiento. Interesa destacar que es a partir de esta Ley que se define la propiedad colectiva, y el formato de uso y goce, a contrapelo de los fundamentos del sistema capitalista. Implicó crear un sistema de finan- 
ciamiento público para que grupos de familias con necesidades de vivienda pudieran acceder a las mismas .En Uruguay la legislación define dos modalidades de cooperativa de vivienda: las de ahorro previo y las de ayuda mutua.

Para explicar muy resumidamente la diferencia entre un tipo y el otro, las personas socias de las cooperativas de vivienda por ahorro previo, aportan en dinero un $15 \%$ del costo de la obra. En el caso de las de ayuda mutua, aportan ese $15 \%$ en trabajo de autoconstrucción. Es en estas últimas que centraré mi ponencia.

El modelo cooperativo comienza a ser una opción relevante para el movimiento de trabajadores/as, ya que encuentra en el mismo la posibilidad real de resolver la histórica necesidad de vivienda. Es con el desarrollo del modelo cooperativo, que se logra, no sólo promover el acceso a la vivienda, sino la calidad y la seguridad en la tenencia, así como también la creación de un hábitat integral, proveyendo a las personas cooperativistas de servicios sociales antes inexistentes, construyendo escuelas, centros de salud, bibliotecas, guarderías; atendiendo la falta de trabajo, haciendo frente al encarecimiento de la alimentación, entre otras cosas. Es con este sentido que desde los distintos sindicatos y grupos de trabajadores y trabajadoras se conforman las primeras cooperativas, mediante una organización colectiva y solidaria. El movimiento cooperativo construyó una herramienta que permitió no sólo construir viviendas, sino también transformar colectivamente la realidad que nos rodeaba.

En este contexto, vale resaltar la creación de la Federación Uruguaya de Cooperativas de Vivienda por Ayuda Mutua (FUCVAM) en el año 1970, que se constituye como uno de los movimientos sociales de mayor relevancia en nuestro país, conformando una organización de carácter nacional en el campo de la vivienda popular y el desarrollo urbano. Desde ese momento pasa a cumplir un rol fundamental: la promoción de proyectos por ayuda mutua y de propiedad colectiva como herramienta eficaz para dar respuesta al déficit habitacional que afectaba a una importante parte de la población.

Es pocos años después de la creación del movimiento cooperativo que ocurre el golpe de estado, en 1973. Durante el período dictatorial el gobierno de facto entendía al cooperativismo de vivienda como una amenaza al orden político y económico neoliberal establecido, por las bases en las cuales se sustenta el cooperativismo: los principios de autonomía económica, democracia, ayuda mutua y solidaridad. En este período el movimiento cooperativo es duramente reprimido, se le retiran todo tipo de apoyos a estos proyectos, suspendiendo la concesión de personerías jurídicas, interrumpiendo los préstamos, dificultando el acceso a créditos, aumentando los intereses y las medidas burocráticas para la gestión del crédito; buscando generar con todas estas medidas congelar a las cooperativas existentes y desalentar la conformación de nuevos grupos. 
Sin embargo, si bien se trató de derribar al movimiento cooperativo, no solo no se logra, sino que el mismo se fortalece como actor social representante de la lucha y acción del movimiento popular, trascendiendo el ámbito de la vivienda. A modo de rescatar la fuerza de la lucha de este movimiento se puede mencionar la promoción de la huelga de pagos de 1983 en la que se resuelve no pagar al Banco Hipotecario del Uruguay (el organismo público financiador de esa época) el reajuste del $15 \%$ de ese año del gobierno, y el impulso del plebiscito para la anulación de la medida de que las cooperativas pasen al sistema de propiedad horizontal (con lo cual se pretendía eliminar el régimen de propiedad colectiva), donde se logran juntar unas $300 \mathrm{mil}$ firmas; teniendo por tanto un rol protagónico en la vuelta a la democracia (Machado, 2016).

Con la reapertura democrática y entrada la década de los noventa las cooperativas se enfrentan nuevamente a desafíos como la falta de acceso a tierras y la falta de financiamiento. Ante esto se generan movilizaciones importantes como la ocupación de tierras para reivindicar el valor del suelo urbano en las áreas centrales. En el 2005 con la llegada del primer gobierno progresista al gobierno (Frente Amplio), comienza un nuevo período para las cooperativas: tanto en presupuesto como en la promoción de nuevos proyectos. En 2008 con la Ley N. ${ }^{\circ} 18.407$ se reglamenta el funcionamiento general del sistema cooperativo. El capítulo quinto está dedicado al cooperativismo de vivienda y viene a complementar la reglamentación de la Ley Nacional de Vivienda y sus respectivas leyes modificativas.

En resumen podemos decir que, a partir de los programas pilotos de 1966, en los últimos 50 años, se logró desarrollar en Uruguay un sistema social de producción de hábitat, basado en la construcción colectiva, la autogestión, la propiedad colectiva, y el financiamiento público (Nahoum, 2013). El modelo cuestiona algunas de las bases fundamentales de la sociedad actual, como ser el individualismo, el consumismo, la empresa privada y el mercado como ejes centrales; y en lugar de eso refuerza valores de solidaridad, en defensa del hábitat y la vivienda como derechos y no como mercancía; instando al Estado a cumplir su función como garante de derechos (Nahoum, 2013). Es por esto que el modelo opera no solamente como una vía de solución al problema de la vivienda, sino también como movimiento social difundiendo ciertos valores y principios, y vinculandose con otras organizaciones sociales que defienden esos mismos principios.

\subsection{LAS BASES DEL MODELO}

El modelo de cooperativas por ayuda mutua, se sustenta en aunar los esfuerzos del estado que aporta el financiamiento y controla el proceso de construcción de las viviendas, con la autorganización de los socios y las socias 
de la cooperativa que son quienes gestionan el proyecto y aportan a su vez mano de obra mediante la autoconstrucción. Para que esto sea posible, los y las participantes deben capacitarse para asumir las funciones a desempeñar en la gestión y durante la obra. A su vez la ley creó junto con las cooperativas de vivienda, los institutos de Asistencia Técnica (IAT), que tienen la función de acompañar el proceso de la cooperativa, brindando un servicio interdisciplinario, técnico y profesional en servicios jurídicos, de educación cooperativa, financieros, económicos y sociales a las cooperativas.

Hoy en día las cooperativas por ayuda mutua (entre las ya habitadas y las que se encuentran en trámite o proceso de obra) suman un total de 515 cooperativas, lo cual se corresponde a unas 22.200 familias $^{1}$.

En la actualidad, las cooperativas tienen que tener un mínimo de diez socios o de seis en el caso de reciclajes y en ambos casos el máximo no podrá superar los cincuenta socios. A su vez se establecen como condiciones de ingreso a la cooperativa, un tope de ingresos por familia, y el requisito de no ser propietarias/os de una vivienda.

Si bien cada proyecto de cooperativa de vivienda, tiene sus características particulares, expondré los puntos en común como bases del modelo 3.

La organización cooperativa: ser parte de una cooperativa de vivienda exige que el grupo se organice y capacite para gestionar la construcción de las viviendas, $\mathrm{y}$ muchas veces hablamos de familias que no tienen experiencia previa en este tipo de tareas. Ante esto la gestión como cooperativa aparece como un aspecto clave, ya que se da como el mejor camino para poder desarrollar una gestión basada en la ayuda mutua y en la participación democrática, en la división de tareas y en los objetivos que se plantea el grupo. La organización cooperativa aparece como un elemento clave que contribuye a fortalecer la capacidad de hacer del grupo.

La ayuda mutua: podemos decir que es un recurso económico, pensando que es el aporte del 15\% de mano de obra que sustituye parte de la mano de obra profesional contratada, lo cual hace que esta opción aparezca como una opción idónea para una población con escasos recursos, que se organiza colectivamente y aporta trabajo para abaratar costos de obra. Sin embargo la ayuda mutua es mucho más que esto ya que implica la posibilidad de que las personas socias de la cooperativa refuercen sus posibilidades de gestión y control de los recursos, participando activamente de la construcción de sus propias viviendas. Este proceso genera una cohesión en el

1 Datos a diciembre de 2017. Fuente: https://www.fucvam.org.uy/situacion-demograficade-fucvam/ 3 La siguiente clasificación sobre las bases del modelo, es extraída de lo expuesto por Nahoum (2013) «Algunas claves. Reflexiones sobre aspectos esenciales de la vivienda cooperativa de vivienda por ayuda mutua». Trilce, Montevideo. 
colectivo, creando valores de solidaridad en la resolución colectiva del acceso a la vivienda. La ayuda mutua no se ve sólo en la obra, sino también en los proyectos sociales (tanto actividades culturales como en la construcción de servicios sociales para el barrio) y la organización colectiva generada en la pre obra, y en la pos obra, creando una identidad grupal mediante el esfuerzo colectivo.

La autogestión: es la herramienta que permite el uso más adecuado de los recursos. Es lo que permite que sea el grupo cooperativo quien tome todas las decisiones. Refuerza el concepto de pertenencia y el compromiso del grupo con la gestión que están llevando adelante. A su vez permite bajar los costos del proyecto, eliminando los costos de intermediación, permitiendo que una franja más amplia de familias puedan acceder a la vivienda. Son los socios y las socias de la cooperativa quienes administran su propio trabajo, incluyendo todos los aspectos de esta gestión, desde las horas aportadas en autoconstrucción, como todas las horas de trabajo dedicadas al sostenimiento del proyecto de la cooperativa.

El régimen de tenencia de la propiedad colectiva (uso y goce): que las cooperativas de ayuda mutua de Uruguay sean de usuarios implica que la propiedad de las viviendas, es de toda la cooperativa, y no de cada familia individualmente. La cooperativa concede a cada familia el uso y goce de una vivienda concreta. La propiedad es colectiva lo cual opera como un factor de unión entre las socias, que a su vez pone en valor el uso y mantenimiento de los espacios comunes y los equipamientos colectivos. A su vez, esta modalidad permite evitar la especulación que se podría generar en cuanto a la venta y alquiler de las viviendas, siendo la cooperativa en su conjunto quien administra el uso de las mismas.

El financiamiento público: este aspecto permite que un importante margen de la población logre acceder a la vivienda, siendo que hablamos de una población que no podría hacerlo por otros medios (compra en el mercado, acceso a préstamos, etc.). El apoyo estatal ha jugado un papel fundamental en el desarrollo del movimiento cooperativo. Las cooperativas pueden solicitar al Ministerio de Vivienda préstamos con garantía hipotecaria para la construcción de sus viviendas y éstos serán otorgados de acuerdo a las condiciones vigentes en el Plan Quinquenal de Vivienda, los Reglamentos de Subsidio a la Demanda Habitacional, Reglamentos de Préstamo y Producto. Los préstamos se estructuran a 25 años con un interés cercano al 5\% en unidades reajustables. El estado aporta el $85 \%$ del valor de $\mathrm{de}^{2} 4$ tasación definido y las cooperativas el restante $15 \%$. Desde el movimiento

2 Unidad reajustable: es una unidad de medida que se reajusta en función del aumento de los salarios del país, ese aumento se mide a través del Î́ndice Medio de Salarios (IMS) que también fue creado por la Ley de Vivienda. 
cooperativo se entiende que el repago de las cooperativas de los préstamos otorgados, funciona o debería funcionar como una inversión que permita seguir financiando nuevos proyectos.

El asesoramiento técnico: como ya fuera mencionado, la Ley establece la creación de institutos de asesoramiento técnico y profesional, los cuales son fundamentales para lograr poner en marcha los proyectos de vivienda. Se establece que las tareas a desarrollar son organizar al grupo cooperativo; formar en principios cooperativos; capacitar para la gestión; asistencia técnica en todas las etapas del proyectos y en todas las tareas administrativas; y la asistencia y asesoramiento para el otorgamiento de las viviendas, y la conservación de la propiedad colectiva. Los IATS al tener una exigencia normativa de no generar excedentes, son entidades sin fines de lucro, que suelen elegir como personería jurídica, la cooperativa de trabajo, para ejercer sus funciones.

El papel de FUCVAM: ha sido fundamental para el desarrollo del modelo, logrando cohesionar al movimiento y su objetivo de conquista del derecho a la vivienda. FUCVAM ha pasado por distintas etapas, con direcciones más abocadas al diálogo y otras más combativas; momentos de conciliación con las autoridades públicas, y otros de mayor antagonismo; pero siempre ha marcado un hilo conductor, siendo guía del movimiento (Nahoum, 2013). Por otra parte siempre ha buscado generar acuerdos con otros colectivos y movimientos sociales, lo que le ha permitido fortalecerse en sus reivindicaciones.

"La importancia de FUCVAM en el desarrollo del sistema cooperativo podria sintetizarse, en definitiva, diciendo que sin FUCVAM habría cooperativas de vivienda y con FUCVAM hay un movimiento cooperativo de vivienda.» (Nahoum, 2013:27).

\section{Algunas claves para el desarrollo del modelo}

El acceso a la vivienda aparece como una necesidad básica de todas las seres humanas.

Como se repasara en el inicio, cuando hablamos de necesidad podemos pensar que existe mucha historia y trayectoria al respecto, cuando pensamos en la organización y la movilización de la clase trabajadora, así como tantos otros colectivos y movimientos sociales, nucleados en base a demandas concretas asociadas a ciertas necesidades.

Podemos hacer referencia también a épocas de crisis económicas, donde son las organizaciones colectivas — como las cooperativas- quienes adquieren mayor capacidad de resiliencia, organizadas a partir de ciertas necesidades. 
Efectivamente podemos decir que la necesidad aparece como una forma de activación; pero, ¿qué entendemos por necesidad? Es al respecto que entiendo que las necesidades no deberían ser entendidas sólo como carencias, ya que cuando se asume la necesidad sólo como carencia, la misma asume con más fuerza la falta de algo. Por esto es que se vuelve fundamental desentrañar el carácter potencializador de la necesidad. Tomar conciencia de este carácter potencial, permite a los colectivos prevenir la reducción de las necesidades en satisfactores estandarizados, genéricos e impuestos; permite motivar y movilizar y — por qué no- organizarse colectivamente.

La necesidad de acceder a la vivienda entendida desde una forma integral como un derecho no garantizado, ligada intrínsecamente a la problemática que la genera, permite trascender la visión que tengamos de la misma, y poner límites a las fuerzas que la generan. Para esto aparece como fundamental la participación social en la resolución de esta necesidad de acceder a la vivienda, y la autonomía como movilización para actuar con discernimiento en la búsqueda de satisfacción de la misma. Es necesario desarrollar una autonomía crítica, para cambiar las reglas y prácticas, consolidando nuevas formas de entender y satisfacer necesidades que puedan devenir en formatos contrahegemónicos.

Cuando hablamos de cooperativas debemos incluir la idea de transformación, con una lógica antagónica a la del beneficio o la simple resolución de necesidades específicas. La propia definición de cooperativa nos habla de necesidades que van más allá de lo económico, y se sustentan también en lo social y lo cultural, como herramientas útiles para transformar nuestra realidad, una sociedad que claramente no está basada en los principios que se puedan promover desde el cooperativismo. Así el cooperativismo logra esta impronta cuando, aun teniendo su origen de conformación en base a necesidades concretas, logra problematizar y politizar las mismas, para desentrañar y transformar la realidad que las engendra. $Y$ desde esta perspectiva y entendimiento, estamos hablando del cooperativismo como cosmovisión, como ideología que trasciende la satisfacción puntual de una necesidad.

Entiendo que el caso uruguayo aparece como un ejemplo de esa conciliación entre necesidad - de vivienda - e ideología, de pensar que la resolución de esa necesidad puede darse de otra forma, de una forma colectiva, y escapando a las reglas especulativas del mercado que deslegitiman el acceso a la vivienda como derecho.

Entendiendo la resolución del acceso a la vivienda, desde una propuesta cooperativa de cesión de uso, aparecen como claves para pensar el desarrollo de este modelo:

- Repensar el derecho a la vivienda desde la propiedad colectiva y la cesión de uso, cambiando la concepción que tenemos del acceso a la 
vivienda, que prima la especulación y su valor de cambio (compra, alquiler), sobre su valor de uso: la vivienda como derecho.

- Tener incidencia en la gestión mediante la organización cooperativa, llevando adelante proyectos autogestionados y democráticos.

- Pensar el rol de la administración pública en el fomento de este tipo de proyectos, y el rol de la intercooperación entre distintos proyectos para lograr un modelo cohesionado que permita incidir en la política pública de vivienda.

- Ampliar la idea de vivienda, incluyendo también la idea de hábitat y la construcción de espacios comunes y servicios sociales acorde a las necesidades de la población, y que sean construidos respetando las postulados de sostenibilidad ambiental.

Implica pensar también qué tipo de ciudad queremos construir para vivir, no sólo en cuanto al acceso a la vivienda como el ámbito privado de reproducción; sino por el contrario intentando romper con esa lógica de público-productivo, privado-reproductivo. Significa entonces pensar la ciudad en términos más amplios, en cómo entendemos la construcción de los espacios colectivos, la sostenibilidad de la vida, las relaciones sociales, la construcción de comunidad, el vínculo rural-urbano; para poder así apropiarnos también de la construcción del derecho a la ciudad:

"(...) la cuestión de qué tipo de ciudad queremos no puede separarse del tipo de personas que queremos ser, el tipo de relaciones sociales que pretendemos, las relaciones con la naturaleza que apreciamos, el estilo de vida que deseamos y los valores estéticos que respetamos. El derecho a la ciudad es por tanto mucho más que un derecho de acceso individual o colectivo a los recursos que esta almacena o protege; es un derecho a cambiar y reinventar la ciudad de acuerdo con nuestros deseos. Es, además, un derecho más colectivo que individual, ya que la reinvención de la ciudad depende inevitablemente del ejercicio de un poder colectivo sobre el proceso de urbanización. La libertad para hacer y rehacernos a nosotros mismos y a nuestras ciudades es (...) uno de los más preciosos pero más descuidados de nuestros derechos humanos.» (D. Harvey, 2013: 20)

$\mathrm{Y}$ es frente a esto que el acceso a la vivienda pensado desde el cooperativismo y la cesión de uso, aparece como una opción viable a continuar desarrollando. Es necesario trascender una mirada utilitarista e individual de satisfacer necesidades, para fortalecer la creación de entidades cooperativas que logren forjar valores que permitan generar y hacer otro tipo de sociedad. 


\section{Bibliografía}

Harvey, D. (2012) «Ciudades rebeldes. Del derecho de la ciudad a la revolución urbana» Ediciones Akal, Madrid-España.

Nahoum, B. (Compilador) (2008) «Una historia con quince mil protagonistas. Las cooperativas de vivienda por ayuda mutua uruguayas», Intendencia de Montevideo-Junta de Andalucía.

Nahoum, B. (2013) «Algunas claves. Reflexiones sobre aspectos esenciales de la vivienda cooperativa de vivienda por ayuda mutua». Trilce, Montevideo.

\section{Documentos consultados}

«La política de vivienda y las cooperativas de vivienda en Europa» Observatorio Vasco de la Vivienda, 2012, disponible en: http://www.garraioak.ejgv.euskadi. eus/r41-ovad02/es/contenidos/informacion/ovv_a_pc_eu_002/es_ovv_admi/ adjuntos/INFORME_Politicas\%20Vivienda_UE_es.pdf

\section{Páginas consultadas}

http://www.laborda.coop/es/

https://www.entrepatios.org/

http://desazkundea.org/language/es/grupos-de-trabajo/etxekoop/

https://www.fcvcam.org/historia-del-cooperativismo.php

http://masqueunacasa.org/es 